\title{
RESEARCHPAPER
}

\section{Effect of Pseudomonas fluorescens and Trichoderma spp. on growth, yield and stem rot disease of groundnut}

\author{
R.B. Dhage and C.T. Kumbhar \\ Zonal Agricultural Research Station, Sub-montane Zone, Shenda Park, Kolhapur (M.S.) India
}

Article Info : Received : 06.11.2017; Revised : 03.03.2018; Accepted : 17.03.2018

Effect of Pseudomonas fluorescens and Trichoderma spp. on stem rot of groundnut incited by Sclerotium rolfsii was evaluated in a field experiment conducted during Kharif, 2014-15. Combined seed treatment with tebuconazole, P. fluorescens and Trichoderma spp. in conjunction with application of P. fluorescens and Trichoderma spp. to soil and, the treatment in which both, P. fluorescens and Trichoderma spp were altogether inoculated to seed and soil significantly reduced the intensity and incidence of stem rot disease in groundnut. These two treatments also augmented seed germination, shoot length, branching, dry plant weight and dry pod yield significantly.

Key words : Pseudomonas fluorescens, Trichoderma spp., Sclerotium rolfsii, Stem rot of groundnut

How to cite this paper : Dhage, R.B. and Kumbhar, C.T. (2018). Effect of Pseudomonas fluorescens and Trichoderma spp. on growth, yield and stem rot disease of groundnut. Asian J. Bio. Sci., 13 (1) : 10-15.DOI : 10.15740/HAS/AJBS/13.1/10-15. 